\title{
Cosmic Rays and the Origin of Species*
}

\author{
By Dr. H. Hamshaw Thomas, M.B.E., F.R.S.
}

$\mathrm{T}^{\mathrm{H}}$ $\mathrm{HE}$ origin of species in Nature is still one of our greatest outstanding problems, and consequently any fresh information which seems to bear on the question is worthy of scrutiny. The object of this communication is to suggest a new direction in which inquiry may be useful. Our present knowledge seems to indicate that species in Nature are far more constant than they were formerly thought to be. Variation seems to depend on the regrouping of the different genes of the parents: it is limited by the combination possibilities of the genes and is less influenced by the environment. Hybridisation cannot be regarded as a sufficient explanation of the origin of new species unless accompanied by nuclear changes. But, on the other hand, there can be no doubt of the reality of mutations. Spartina Townshendi is a new species which has originated and spread under observation, and there is evidence which suggests that many other forms may have originated in a similar way in Nature. Among plants and insects raised in cultivation, many mutations have been recorded and studied. Thus while we have evidence of plant species existing over very long periods essentially unchanged, as we know from fossil and sub-fossil evidence, we also know that sudden change is possible. It is difficult to conceive that such changes are spontaneous; we must search for some external cause in the environment.

In a recent survey of the experimental production of mutations, N. W. Timoféeff-Ressovsky ${ }^{1}$ has shown that treatment with short-wave radiations and high-speed electrons is so far the only effective method of inducing mutations giving constant and measurable results. All other treatments hitherto applied have led to no definite conclusions. At the same time, numerous investigations of the effect of X-rays on nuclear structure $^{2}$ seem to indicate that radiation may produce those cytological changes which are often associated with specific differences. There is thus no doubt that new forms can be produced by the action of penetrating rays and electrons on dividing cells ${ }^{3}$.

But ever since Müller's sensational discovery of the effects of X-rays, there seemed to be little hope of showing that species arose in Nature through short-wave radiations or radioactive particles. Most investigators who have considered

\footnotetext{
* Paper read before the Linnean Society of London on November 21.
}

the question have held that the view "that the mutational process is in general caused by natural radiation is out of the question, as this does not amount to the quantitative values required to evoke mutants experimentally"4. No doubt this is true as regards the disintegration products of radioactive elements, but the recent discoveries of the nature and distribution of cosmic rays have considerably changed the situation.

We now know that photons and charged particles of very great energy are constantly reaching the earth in vast numbers. These particles closely resemble in their properties and effects the secondary corpuscular radiation produced by $\mathrm{X}$-rays and the emanations from radioactive bodies, and there is no reason for supposing that their action on living nuclei would be different. The difference is, however, that while the X-rays in experimental conditions impinge in a dense and continuous beam on the chromosomes, the cosmic rays are generally in the form of a diffuse bombardment by single particles which are, of course, of infinitesimal size. Taking the ionisation as a measure of the activity of the stream of X-rays used in some experiments by Goodspeed and Olson ${ }^{5}$ on Nicotiana, they would be more intense than cosmic rays at sea-level acting for the same time by a figure of the order of $5 \times 10^{7}$. Most of the doses used in radiation genetics have been 1,500 or more times greater. But we may notice that it seems certain that $\mathrm{X}$-rays are effective through their secondary $\beta$-rays, for a correlation has been established by several workers between the ionisation and mutation rate curves, while mutations are also produced by radioactive substances and by cathode rays. There seems to be a threshold value for X-ray action. Small doses have been found to have an effect, while recent work on bacteria favours the view that a bacterium has a definite chance of being hit and killed by a single electron ${ }^{6}$. Thus, in view of what we know about the disintegrating power of high-speed particles, if a gene is a material body carried at a particular spot on a chromosome, it might well undergo structural change if struck by a single one of the high-energy particles originating from an X-ray beam, from a radioactive substance or from cosmic rays*.

While it is possible, as has been already suggested by Dixon ${ }^{2}$, Hurst ${ }^{8}$ and others, that cosmic rays

* The physical basis of gene mutation has been considered by Timoféeff-Ressovsky, Zimmer and Delbrück, Nach, Ges. Wiss. Göttingen, VI, 1, p. $190(1935)$ 
may bring about nuclear changes and mutations, we need evidence that they do so.

Babcock and Collins observed the variation in cultures of Drosophila kept in a tunnel under 140 feet thickness of sandstone, which they assumed to be a screen from cosmic radiation. There was, however, more ionising radiation than in the laboratory where their controls were kept, and the mutation rate in the tunnel was significantly higher $^{9}$. Another experiment ${ }^{10}$ has been carried out with the object of ascertaining whether a colony of mice showed any significant difference in their variation when kept for a year at the bottom of a mine where they were effectively screened from cosmic rays. No significant difference was observed, and the conclusion was suggested that cosmic rays were ineffective in causing mutation. But these experiments scarcely dispose of the question, for though the number of rays which are recorded by a Geiger-Müller counter at sea-level appears considerable, the actual area struck by particles must be extremely small, and it may be years before a hit is made on a chromosome which is in a condition to show a subsequent effect and which gives rise to a visible change. Then it has also been found in X-ray experiments that the majority of the effects produced are lethal, some may be of an internal chemical nature, and only occasionally will a mutation arise showing external morphological change. We must also remember that in the plant world in Nature an exceedingly small fraction, perhaps one six thousandth, of the seed progeny of any individual survive. Consequently the chances of species originating through natural radiation would be small. If we are to find any noticeable results attributable to natural radiation, we must look in those localities in which the ionisation due to the energised particles is more intense.

Recent investigations by various workers ${ }^{11}$ indicate that the ionisation due to cosmic rays falls off rapidly as they pass through the earth's atmosphere. The recent observations with balloons and aeroplanes ${ }^{12}$ show that the ionisation rises more or less exponentially up to the highest point reached $(62,000 \mathrm{ft}$.). At a height of $11,000 \mathrm{ft}$. the intensity of radiation increases about threefold and at $22,000 \mathrm{ft}$. the increase is about tenfold. At $62,000 \mathrm{ft}$. the ionisation is about eighty-three times greater than the sea-level value. The report in The Times of the recent ascent into the stratosphere from the United States mentions an increase of cosmic ray intensity by 150 times. Furthermore, the incoming radiation is not a uniform stream of similar charged particles, and its composition varies with altitude. From our point of view, the occurrence of what are called cosmic ray bursts and of showers ${ }^{13}$ is interesting as they show bundles of ionising particles which, impinging on a mass of sporocytes, are likely to make direct hits on several chromosomes. Compton and Bennett ${ }^{14}$ report that the frequency of these bursts is found to increase more rapidly with altitudes than does the intensity of the total cosmic ray beam. Prof. Compton has recorded bursts on Mount Evans (6,900 ft., lat. 50.58 N.) in which more than $3 \times 10^{8}$ ion pairs were liberated ${ }^{15}$. It may also be noticed that this ionisation is of the same magnitude as that said to have been produced by the X-rays used in experiments by Goodspeed and Olsen in which numerous mutations were produced in the tobacco plant ${ }^{16}$.

These considerations suggest that if nuclear change and consequent mutation is produced by cosmic radiation, it will vary with altitude; and while little mutation may be observable at sea-level, it should steadily increase with altitude. It may be noticed, however, that at high altitudes a latitude effect ${ }^{12}$ has been observed in the intensity of ionisation, the values obtained increasing with the latitude from magnetic latitude $20^{\circ} \mathrm{N}$. up to about $54^{\circ} \mathrm{N}$. The readings made at $22,000 \mathrm{ft}$. in Panama $\left(20^{\circ}\right.$ N.) and Peru $\left(4^{\circ} \mathrm{S}\right.$.) are 29 per cent lower than those in California $\left(41^{\circ} \mathrm{N}\right.$.) and 38 per cent lower than those in Spokane, Washington $\left(54^{\circ} \mathrm{N}\right.$.). On the other hand, the height reached by plants growing on mountains falls steadily with increasing latitude.

It should be thus worth inquiry as to whether there is any correlation apparent between the variation of species and the intensity of cosmic radiation at different points on the earth. Some preliminary inquiries suggest that there may be evidence for such a correlation, and while a few examples may be mentioned, it is clear that the material needs careful collection and analysis before any certainty can be reached. In this quest plants should provide better evidence than animals, owing to the greater uniformity in their nutritional requirements. The distribution and occurrence of animals must depend on the distribution of their food, but the food substances of the plant are uniformly distributed over very wide areas. Plants also have infinitely less power of migration from their centre of origin.

Our inquiries may be made first among cultivated plants, and here some interesting information has been provided by Vavilov in the course of his studies on the geographical distribution of the varieties of important crop plants. Vavilov and his fellow workers ${ }^{17,18}$ have studied the nature and distribution of the varieties of cultivated plants in different parts of the world. He found that in certain regions economic plants are represented by a great number of varieties, and deduced from this, as well as from the occurrence of allied wild forms, that their 
cultivation originated in those areas. The presence of a large number of varieties was explained by the view that the plants have had a longer time in their original home in which to vary. Whether this is true or not, it seems clear from the information published that the areas in which the greatest specific and varietal diversity are found, are the mountain regions of the tropics and warm temperate regions, while the varieties in the lowlands are much less numerous even though extensive cultivation has been carried on, as in Egypt, for a very long period. Thus Vavilov found sixty varieties of Triticum vulgare in Afghanistan, fiftytwo in Persia, forty-six in Baluchistan, while India has thirty-two, Mongolia thirty-one, and Italy twelve. In Afghanistan, fifty varieties of Triticum compactum were also found, and many of these wheat varieties were endemic. The durum group of wheats showed its greatest diversity in Abyssinia, where there are many more forms than in Egypt or North Africa.

By similar work, Vavilov distinguished seven or eight centres in which crop plants show such variety as to suggest that they may be considered as the foci of world agriculture; almost all these are on high mountains or plateaux, not more than $40^{\circ}$ from the equator. In addition to Afghanistan and Abyssinia, the mountains of Central America from Chile to Mexico are very rich in varieties of maize, potatoes, beans, all of which are grown up to $12,000 \mathrm{ft}$. in Peru ${ }^{19}$, cotton and fruit trees, as well as forms like the agaves and many of the ornamental plants of our gardens. Other centres are the southern ranges of Caucasus, the southeastern Himalayas, Asia Minor and Portugal, together with a tract in western China not yet localised. In most of these areas cultivation has not, so far as we know, been very extensive compared with that in many lowland regions of the world, and if there was no external cause of varia. bility at high altitudes one would expect the greatest number of variations to appear in the areas where crop production had been most extensive and the chances of mutation consequently greatest.

\footnotetext{
${ }^{1}$ Timoféeff-Ressovsky, N. W., "The Experimental Production of Mutations", Biol. Rev., 9, 411 (1934).

${ }^{2}$ Huskins, C. L., and Hunter, A. W. S "Effects of X-Radiation on Chromosomes in the Mierospores of Trillium erectum, Linn.", Proc. Roy. Soc., $B, 117,22(1935)$.

"For a brief review of the fleld of radiation genetics, see Oliver,

C. P., Quart. Rev. Biol., 9, 381 (1934). Hereditas, 20,235 (1935).

8 Olson, A. R., and Lewis, G. N., NATURE, 121, 673 (1928).

- Pugsley, A.'T., Oddie, T. H., and Eddy, C. E. "The Action of $\mathrm{X}$-Rays on Certain Bacteria", Proc. Roy. Soc., B, 118, 276 (1935).

'Dixon, H. H., NATURE, 123, 981 (1929).

8 Hurst, C. C., "The Mechanism of Creative Evolution", p. 199, Cambridge (1932).

Babcock, E. B., and Collins, J. L., "Does Natural Ionising Radiation Control Rate of Mutation ?", 'Proc. Nat. Acad. Sci., 15, 623 (1929).

${ }^{10}$ Engelstad, R. B., and Moxnes, N. H., "Possible Action of Cosmic Rays on Living Organisms", NATURE, 134, 898 (1934).

${ }^{11}$ Papers and discussions on Cosmic Radiation at the International Conference on Physics 1934. Cambridge (1935).

${ }_{12}$ Bowen, I. S., Millikan, R. A., and Neher, H. V., "Latitude Effect at Very High Altitudes". International Conference" on Physics, London, 1934. Papers and Discissions, Vol. 1. Cambridge, 1935.

(I.C.P. in later references), p. 206 . p. 203 .

${ }_{14}$ Compton, A. H., and Bennett, R. D., "Cosmic-Ray Bursts at Different Altitudes",' I.C.P., p. 225 .

${ }_{15}$ Compton, A. H., "Magnitude of Cosmic-Ray Bursts", NATURE, 134, $1006(1934)$.

16 Goodspeed, T. H., and Olson, A. R., "The Production of Variation in Nicotiana Species by X-Ray treatment of Sex Cells", Proc. Nat. Acad. Sci., 14, 66 (1928).

12 Vavilov, N. I., "Mexico and Central America as the Principal Centre of Origin of Cultivated Plants of the New World", Bull. Applied Bot. Genet. and Plant Breeding, 26, 179; 1931. "The Problem of the Origin of the World's Agriculture", London, 1931. "The Rol of Central Asia in the Origin of Cultivated Plants", Bull. Applied Bot., etc., 26, 31 (1931).

${ }^{18}$ Watkins, A. E., "The Origin of Cultivated Plants, Antiquity, 7, 73 (1933).

19 Hitcheock, A. S., "A Botanical Trip to Ecuador, Peru, and Bolivia", Rep. Smithsonian Institution for 1924, p. 346, Washington (1925).
}

(To be continued.)

\section{Progress in Enzyme Chemistry*}

$\mathrm{T}$ HERE is once more definite progress in enzyme chemistry to report, largely due to the resumption of the study of enzymes from the purely chemical point of view. The appreciation on the Continent of the concept adumbrated by Willstätter that enzymes are composed of a colloid carrier, and of one or more specific active groups through which they are associated with or bound to the substrate on which they act, has opened the way for practical work which, inspired by the successful isolation by Sumner and by Northrop of highly active enzyme preparations in crystalline form, is affording some clues to their

- This article is based upon (but much expanded) a paper read on September 6 by Prof. E. Waldschmidt-Leitz before Section B (Chemistry) at the Norwich meeting of the British Association. inner structure. Willstätter postulates the colloidal carrier as responsible for the catalytic activity and for the stability of the active group, which latter controls the specificity. Kraut has recently suggested the names Agon for the active group and Pheron for the carrier, which have been adopted by Oppenheimer in his books.

Willstätter's conception differs very little from that advanced by the Armstrongs so long ago as 1913, when the dual function of an enzyme in holding the hydrolyte and determining its hydrolysis was enunciated. According to them, the enzyme, which was a large colloid molecule with a particular, active centre, consisted of an acceptor together with an agent. The acceptor was 